\title{
NEMŠKO-SLOVENSKI STIKI V SLOVENSKI TOPONIMIJI
}

0 Nemško-slovenski jezikovni stiki segajo že v 8. stol., obravnavali pa so jih številni jezikoslovci, med katerimi velja omeniti predvsem Primusa Lessiaka, Karla Štreklja, Jakoba Kelemina, Ivana Koštiála, Frana Ramovša, Franceta Bezlaja, Eberharda Kranzmayerja, Otta Kronsteinerja, Brigitte Mader, Heinza-Dietra Pohla, Georga Holzerja, Angelo Bergermayer in Huberta Bergmanna. Našteti raziskovalci so se zaradi pomanjkanja drugih pisnih virov za starejše razvojne faze slovenskega jezika naslanjali prav na zapise osebnih in zemljepisnih imen in s tem pripomogli $\mathrm{k}$ boljšemu razumevanju njihovega besedotvorja, procesov medjezikovne substitucije in adaptacije. $\mathrm{V}$ prispevku se obravnava osem slovenskih zemljepisnih imen, ki so nastala v medjezikovnem stiku, vendar pri treh to velja le za njihove nemške oblike. ${ }^{1}$

1 Nemci so prevzeli in oblikoslovno adaptirali slovenska zemljepisna imena, pri čemer so Slovenci v večji ali manjši meri sprejeli te nemške oblike. Na ta pojav je svoj čas opozoril že Štrekelj (1906: 48), ko je pojasnil krajevno ime Činžat (nem. Zinsat) iz slovenskega apel. senožet, mi pa ga ponazarjamo na primerih krajevnih imen Njiverce in Stoperce. Nasproten primer slovenske adaptacije nemškega imena je Vojnik, ki je nastal s transpozicijo iz Hoheneck s pomenom 'visoko brdo' (Torkar 2011: 358).

\section{Njiverce}

Njiverce so vas v občini Kidričevo (do 1994 občina Ptuj), ki je še 1. 1931 štela le 94 prebivalcev (PKLS 1997: 206), danes pa že okrog 700 (spletni vir 1). V historičnih virih je dobro izpričana, zapisi pa nam omogočajo zasledovanje razvoja oblike krajevnega imena: 1220-1230 Glibatsdorf, 1369 Chniebatzdorf, Chniewestorf, 1390 Chniebotzdorf, 1440 Chnyerrczen, Gimberczen, 1450 Gnibercz, 1461 Gimbertz, 1780 Newerzen, 1822 Niwerzen, windisch Niverza, FK 1824 Niverzen (k.o. Gerečja vas), 1883 Niverce, 1910 Nivrce, 1933 Niverce, 1937 Njiverce. Sodobne imenske oblike so: Njiverce, $v$ Njívercah, njíverski, Njíverčani (Jakopin idr. 1985: 181).

Snoj (2009: 283) izvaja Njiverce kot "prvotno zelo verjetno *Njivarice" " iz apel. *njivar, vendar je ta razlaga problematična zlasti glede na historične zapise. Če bi bila podstava toponima *njiva, ni mogoče pojasniti srednjeveških oblik z vzglasnim $g_{-}$, ki se pri tej besedi sicer pojavlja v koroških narečjih, npr. rožansko yńíwa za 'njiva', tudi Megiser 1744 ima gniva in Gutsman 1789 (Ramovš 1924: 119), kar je gotovo pojav,

\footnotetext{
* Inštitut za slovenski jezik Frana Ramovša, ZRC SAZU, Novi trg 4, 1000 Ljubljana, Slovenija; silvo.torkar@zrc-sazu.si

1 Za pripombe in nasvete pri korigiranju besedila se zahvaljujem kolegici prof. dr. Metki Furlan.
} 
mlajši od 13. stol. Nasprotno je lažje pojasniti izgubo vzglasnega $g$ - v mlajšem narečnem razvoju, npr. prekm. nêvka, nêfka za 'gnev' (Bezlaj 1976-2007/I: 152).

Najstarejši zapis 1220-1230 Glibatsdorf omogoča domnevo, da je slovenska podstava toponima verjetno narečni apel. glivec '(goba) štorovka' (Pleteršnik) ali glívci [g'li:fci] '(gobe) sivke' (Rajh 2010: 63), izpričan na Štajerskem (na Pohorju in v Prlekiji). V toponimiji tega območja sta izpričana še zaselka Glivno in Glivnik (TTN5), ki sta izpeljana iz narečnega apel. glíva 'štorovka' (Pleteršnik 2006: 217). Na ponemčenem Štajerskem srečamo tpn Gleiming (1150 Glibenich, 1272 Glimnich), ki ga izvajajo iz *Glivnik (Lochner v. Hüttenbach 2008: 93, ANB 1989-2004/6: 417). Domnevati je mogoče, da sta bila apelativa gliva in glivec rabljena sinonimno in da se za nem. zapisom Glibatsdorf skriva slovenska oblika *Glivec, ki pa je imela konkurenčno imensko obliko *Glivna vas. Z asimilacijo $l-n>n-n$ se je iz *Glivna vas verjetno razvila oblika *Gnivna vas. Zapisi 14. stol. (Chniebatzdorf, Chniewestorf, Chniebotzdorf) odražajo že prenarejeno vzporedno krajevnoimensko obliko *Gnivec. Ker pogoja za nastanek $n$ $\mathrm{v} *$ Glivec ni, je treba predpostaviti vpliv disimilirane slovenske variante *Gnivna vas. Iz oblike *Gnivna vas je bilo najverjetneje izpeljano stanovniško ime *Gnivenci, v tož. smeri *Gnivence, ki je začelo nastopati v vlogi krajevnega imena, kot se je to marsikdaj dogajalo, npr. Dragonja vas (iz *Dražigojna vas, 1527 Drassiganawess), ki je še 1822 izpričana z imenom Dražence (Schmutz 1822: 270). Zapisi 1440 Chnyerrczen, Gimberczen, 1450 Gnibercz odražajo imensko obliko *Gniverce, ki je rezultat delnega glasovnega ponemčenja izglasja, primerljivega s tistim pri imenu Stoperce (iz *Stopence). Dragoceni bi bili zapisi za 16. in 17. stol., iz katerih bi videli, kdaj je odpadel vzglasni $g$ - Pri poknjiževanju imena so šele uredniki KLDB (1937) z vstavitvijo črke -j- izpeljali nedvoumno naslonitev na apel. njiva.

\section{Stoperce}

Po enakem modelu kot Njiverce je bilo najverjetneje tvorjeno tudi krajevno ime Stoperce v občini Majšperk (do leta 1994 občina Ptuj) z imenskimi oblikami: v Stópercah, stóperški, Stóperčani (Jakopin idr. 1985: 275). Ime je izpričano v zgodovinskih virih, začenši z letom 1438: Stamphendorf, 1440 že Stamphern, 1448 Stainpharren, 1780 Stupricza, 1792 Stopenzen, nar. Stopernce (Žunkovič 1927: 75), FK 1825 Stopperzen (k.o. Stoperce), 1872 Stoperce, 1894 Stoperci, 1904 Stoprce.

Štrekelj (1906: 60) je rekonstruiral krajevno ime Stoprce kot *Stoparci. Oblika na -ce (iz -ci) je po njegovem nastala iz *Stoparji (iz apel. stopar 'kdor dela s stopami’) pod vplivom bližnjih krajevnih imen na -ci. Toda ljubiteljski jezikoslovec Žunkovič je o tem imenu pozneje priobčil kratko imenoslovno črtico (Žunkovič 1927: 75), kjer je navedel pomemben zapis iz leta 1792: Stopenzen. Srednjeveška zapisa 1438 Stamphendorf in 1440 Stamphern po njegovem kažeta, da se je kraj prvotno imenoval Stopno (kar so Nemci prevedli v Stamphen), prebivalci pa Stopenci, kar so Nemci prevedli v Stamphern. V zapisu iz leta 1792 je ohranjena stara slovenska oblika Stopenci, medtem ko je današnje nar. Stopernce nastalo s križanjem med slovensko in nemško obliko. V bližini, pri Makolah, obstaja tpn Stopno, ki pa ni bil preveden v nemščino, saj je v 13. stol. zapisan s Stopendorf, v 19. stol. pa kar s Stoppno. Žunkovič 
je na podlagi vseh historičnih zapisov prepričljivo ovrgel Štrekljevo rekonstrukcijo in dobro utemeljil svojo. Snoj (2009: 396) kljub vsemu prevzema Štrekljevo razlago imena Stoperce, Žunkovičevo razlago pa brez komentarja podaja v drobnem tisku med opombami.

2 Nemci so krajevno ime adaptirali ali prevedli, medtem ko so Slovenci ohranili svojo imensko obliko, ki se je spreminjala v skladu z domačim glasovnim razvojem. Takšen primer predstavljata krajevni imeni Vižmarje in Goriča vas.

\section{Vižmarje}

Vižmarje so nekdanja vas, ki je od 1. 1975 del Ljubljane. V zgodovinskih virih zasledimo zapise: 1283 Geiselmannsdorf, 1385 Geismanstorf, 1421 Geysmerstorf, 1497 Geissmannsdorf, 1554 Vsmariach, Vsmarich, 1744 Vifchmarie, 1780 Vismarie, FK 1826 Wischmarie, 1843 Vishmerje, 1868 Vižmarje. Sodobne imenske oblike so: v Vižmarjah, vížmarski, Vižmarčani. Ime je prvi skušal razložiti Kelemina (1944: 393), Bezlaj (1965: 115) in Snoj (2009: 461) pa sta njegovo razlago sprejela. Srednjeveški zapisi naj bi dokazovali, da je tpn izpeljan iz nem. atn Gismar, kar naj bi Slovenci z gorenjsko palatalizacijo vzglasnega $g$ - glasovno adaptirali v *Jižmar. Nato naj bi se zgodilo še zlepljenje predloga $v$ z imenom. Tpn naj bi potemtakem predstavljal tožilnik množine od os. i. *Jižmar (*Jižmarje), skupaj s predlogom pa *Vjižmarje. Ta razlaga se je izkazala kot malo verjetna, takoj ko je postalo jasno, da je v slovensko-nemškem jezikovnem stiku že od nekdaj prihajalo do substitucij slovanskega $v$ z nemškim $g$ (Torkar 2015: 279). O teh substitucijah nam pričajo stari zapisi slovanskih osebnih in krajevnih imen, ki so jih napravili nemški pisarji.

Že v leto 870 sega zapis Sclagamar za moravskega kneza Slavomirja (Miklošič 1860: 311). Vas Schlammersdorf pri Erlangenu na Bavarskem se v virih navaja 1050 kot Slagamaresdorf in 1169 kot Slagemarsdorf (Schwarz 1960: 258). Nedvomno je tudi Slagomerje, staro ime za Žahenberc v o. Rogatec, nar. Slagómarje, rezultat nemške substitucije slovenskega imena *Slavomirje, le da so ta nemški $g$ prevzeli tudi Slovenci. Zapisi 1436 Slagamer, Slogomer, Slugamer, 1458 Slungomer, Slugomor, Zlogomer, 1489 Slogomer, 1780 Zlagomarie dokumentirajo substitucijo vsaj od 15. stol. dalje. Tudi vas Visole v o. Slovenska Bistrica z imenskimi oblikami na Visolah, vísolski, Visolčani in s historičnimi zapisi 1265-1267 Gyzubel, 1454 Gisuebel, ok. 1500 Gwesswbel, Gussublperg, 1822 Giessgiblberg, windisch Gissule, ima že zgodaj izpričano substitucijo etimološkega slovenskega $v$ z nemškim $g$. Če gre verjeti zapisu iz leta 1822, so občasno tudi Slovenci prevzeli nemški izgovor. Vitomarci v Slovenskih goricah nastopajo v starejših nemških zapisih kot Witmarsdorf in zlasti Wittmansdorf, enkrat samkrat (leta 1500) pa tudi Gittmansdorf.

Glede na dobro dokumentiran pojav substitucije $v \rightarrow g$ smemo zato nemške zapise 1421 Geysmerstorf, 1497 Geissmannsdorf jemati kot glasovno ponemčenje slov. imena *Višemirje oz. substitucijo z najbližjim nemškim imenom na podlagi sozvočnosti. To nem. os. i. je bilo Gis(al)mar oz. Gis(al)man, pojav tovrstne substitucije pa je prikazal že Skok pri imenu Radgona, nem. Radkersburg, kjer so slovensko ime *Radegoj 
Nemci substituirali s svojim Ratger (Skok 1924: 44). V imenu Vižmarje je torej vsebovan slovanski atn *Vyšemirb. *Vyšemirbje je dalo *Višmarje, po zvenečnostni premeni pa Vižmarje. Ta tip premen (nezveneči glas + zvočnik) vidimo v hdn Litožnik < *Ljutošnik, tpn Kozmerice $<*$ Gos(t)merica idr.

Atn *Vyšemirz in *Vyšel'ubъ sta izpričana v 9. in 12. stol. na Štajerskem in Salzburškem (Kronsteiner 1975: 86-87), *Vyšemirz pa pri Čehih v 12. in 13. stol. (Pleskalová 1998: 145) in Poljakih v 13.-15. stol. (Malec 1971: 129). Toponimi iz atn *Vyšemirz so izpričani pri polabskih Slovanih (danes v Nemčiji): Wismar (1211 Wissemer, 1229 Wyssemaria, 1253 Wismaria) (Trautmann 1950: 166) in na Poljskem: Wyszomierz, pred vojno nem. Wissmar (Rospond 1983: 151) in Wyśmierzyce (Malec 2003: 271). Ime Wyszemir se razlaga kot zloženka iz adverbialne oblike *vyše k psl. *vyšbjb 'višji' (Vasmer 1986-1987/I: 378, Valčáková 2007: 23, 26) ali kot sr. sp. primerniške oblike *vyše k psl. *vyšbjb 'višji' (Taszycki 1958: 59, ESSJa 1974-/2: 185)² in *mirs 'mir, sloga'. Toporov ob tem imenu navaja tudi frazem - uganko Čto vyše mira? (Toporov 1993: 61).

\section{Goriča vas}

Goriča vas je naselje v občini Ribnica. V virih se navaja 1241 Weichartsdorf, 1340 Weychartes dorf, 1436 Weykerstorf, 1780 Goricha, Goricha Vass, 1823 Gorizhavaf, rod. Gorizhevafi (Metelkovo gradivo), 1843 Gorizha Vaf (Weikersdorf), 1894 Goriča vas, nem. Weikersdorf. Sodobne imenske oblike so: v Goriči vasi, goričevski, Goríčevljani. Slovenski jezikoslovci se s tem tpn doslej menda še niso ukvarjali, morda tudi zato, ker je videti preveč prozorno, izpeljano pač iz apel. gorica. Toda vsi starejši historični zapisi odražajo nemško verzijo imena, za katero se na prvi pogled zdi, da je polimorfno, torej brez medsebojne etimološke povezave s slovenskim. Vendar nam dva zapisa za tpn Boričevo v občini Novo mesto, namreč 1477 Gorischew in 1780 Goriczhevo, ki odražata občasno glasovno premeno vzglasnega $b$ - v $g$-, pomagata pri spoznanju, da imamo tudi pri tpn Goriča vas opraviti z enako premeno (Torkar 2015: 281). Goričo vas smemo zato rekonstruirati kot *Boritj-ja vbsb. Ime je izpeljano, enako kot Boričevo, le z drugim priponskim obrazilom, iz patronimika *Borič $(<*$ Boritjb), ta pa iz okrajšanega imena *Borъ k atn *Borislavъ. Nemci so prevedli osebno ime *Borič v Weichart (< stvn. Wighart 'drzen borec'), v slovenskem narečju pa je pozneje prišlo do nepovratne premene vzglasja $b$ - v $g$-.

Za slovensko adaptacijo nemške oblike pa gre verjetno pri hibridnem tpn Vikrče (v Víkrčah) pri Ljubljani, ki je v letih 1394 in 1436 zapisan kot Weykers, Waikers, nato 1754 Vickerz, 1776 Weikersdorf, 1780 Vitercze, Witerza, 1823 Wikertsche, 1843 Vikerzhe (Ramovš 1924: 264). Bezlaj (1977: 225, ponatis 2003: 572) ga sicer izvaja iz *vykъrčane, kar sprejema tudi Snoj (2009: 454), vendar je zaradi odsotnosti množinskih oblik v starejših historičnih zapisih ta razlaga manj verjetna.

2 Vasmer, Valčáková in ESSJa sicer na navedenih mestih obravnavajo le dvočlenska atn *Vęčeslavъ in/ali *Bol'eslavъ, ki pa sta tvorjena po istem modelu kot *Vyšemirz. 
3 Imena s podstavo iz enega jezika in priponskimi obrazili iz drugega so hibridna ali heteromorfna imena. Ta tip imen je na Slovenskem razmeroma pogosten, npr. Ruperče, Pirniče, Gunclje (nemško osebno ime in slovensko obrazilo -jb) (Ramovš 1924: 264) ali Prosnid, Jagnjed (slovenska apelativna podstava in starofurlansko obrazilo -ed) (Torkar 2012: 695). V to kategorijo sodijo tudi krajevna imena Vižinga, Ciringa, Temljine in nemška oblika gorskega imena Šmarna gora, ki se glasi Kallenberg.

\section{Vižinga in Ciringa}

Spodnja in Zgornja Vižinga sta vasi v občini Radlje ob Dravi, ki skupaj štejeta nad petsto prebivalcev. V virih sta izpričani že od 12. stol.: 1161 ad Fusingen, 1193-1220 Wosingen, 1278 Vevsing, 1281 Visingen, 1305 Vevsingen, 1375 Vising, 1404 in der Fising, 1401-1432 Fewsingen, 1458 Feusing, 1586 Vising, 1780 Feisig, 1825 Ober Feising, Unter Feising (k.o. Vižinga Zgornja, k.o. Vižinga Spodnja), 1873 Gornja Vižinga, Spodnja Vižinga, 1933 Spodnja Vižinga, Zgornja Vižinga. Sodobne imenske oblike so: na Vižingi, vížinški, Vižinčani.

V imenu Vižinga je mogoče prepoznati starejšo slovensko obliko *Višinje, ki je po elipsi odnosnice pol'e nastala iz hpk *Vyšb k atn *Vyšemirz, *Vyšegojb ipd. s svojilnopridevniškim obrazilom -inje ( $<-y n ' i)$, ali morda tudi *Višina, izpeljanim iz istega hpk z zbirnim obrazilom -ina. Obliko Visingen so ustvarili nemški pisarji iz slovenskega imena *Višinje (ali *Višina) po vzoru nem. tpn na -ingen in -ing. Podobne primere zasledimo pri imenih Bohinj (v 11. stol. nem. Bochingun, Bochingin za *Bohynjb), Bitnje (nem. Vitingen, Veiting, Feichting za *Bytina), Jarenina (nem. Jaringen, Jaring za *Jarina), Nomenj (nem. Neuming za *Č́rnomynjb), reka Mirna (nem. Neiringen za *Nyrina), češko Bechyně (nem. Bechingen, Beching) (Profous 1947-1960/I: 39). Na slovenskem jezikovnem ozemlju so nekdanja osebna imena s podstavo *Vyše- oz. *Vyšvsebovana v zemljepisnih imenih Vižmarje $(<*$ Vyšemirъ), Višprije $(<*$ Vyšepridъ), Višelnica $(<*$ Vyšblb), Vižnica $(* V y \check{s} b n i c a<* V y s ̌ b)$.

Ciringa je vas v občini Kungota tik ob meji z Avstrijo. Predložna raba je na Círingi, pridevniška oblika je cirinški, stanovniško ime ni izpričano. L. 1269 se pojavlja v virih kot Zyerberg, 1480 je zapisana še v obliki Zirnigkh. Na Dolenjskem je več krajev z imenom Cirnik, v 13.-15. stol. pisanih Cernik (Zernich, Cernich, Zernik, Zernikh ipd.), zato verjetno smemo izhajati iz apel. cer 'vrsta hrasta'. Tu je bilo slovensko obrazilo -nik substituirano z nemškim -ing, kot se je to dogajalo na ponemčenem ozemlju današnje Spodnje Avstrije, npr. *Rudnik (1160 Rudnich) je dal današnje Reidling, *Kamnik (1308 Gemnich) pa današnje Gaming (Holzer 2001: 58, 88).

\section{Temljine}

Temljine so vas v srednjem delu Baške doline na Tolminskem, v neposredni soseščini nekdanjega Nemškega Ruta, območja, ki so ga malo pred letom 1250 naselili tirolski kolonisti iz Innichna (Kos 1948: 17). V virih so izpričane: 1377 villa de Telmino, villa de Telmine, 1515 Tulminih, 1523 Tumblinckh in die supp Graffenpach gehörig, 1535 
Tulmin, 1566, 1600, 1648 Tamlin, 1666 Tulmineh, Tulmine, 1780 Tulmina, Tumlina, FK 1822 Tumlina (k.o. Kneža). Sodobne imenske oblike so: na Temljínah, temljánski, Temljáni (prim. podobno tvorjenost pri tolminskem tpn Péčine: na Péčinah, pečánski, Pečáni). Na sosednjem Grahovem še poznajo tudi metatezirane oblike Tel(j)mine, na Tel(j)mineh. Krajevno ime Temljine je Kelemina (1951: 180) zaradi določene podobnosti srednjeveških historičnih zapisov povezoval s tpn Tolmin in ga s tem uvrščal v substratno plast.

Temljine je prvi skušal konkretneje besedotvorno razčleniti Snoj (2009: 424). O tem imenu sicer pravi, da je nejasno in da se je, sodeč po najstarejših zapisih, razvilo iz edn. *Tblml'ina ali *Tblml'ina, kar verjetno izvira iz svojilnega prid. *Tblml'b oz. *Tblml'b k nekemu neznanemu os. i. Snoj rekonstruira os. i. ${ }^{*} T$ b $l m b$, za katerega domneva, da je prevzeto iz rom. *Tolomeius (iz lat. Ptolomaeus), v katerem je drugi o odpadel po sinkopi. Prvotno slovansko *Tblml'a vbsb naj bi po univerbizaciji dalo *Tblml'ina, v rednem glasovnem razvoju *Teml'ina, pozneje množinsko Temljine. Pri tej rekonstrukciji se naslanja na svojo razlago tpn Gameljne pri Ljubljani, ki ga izvaja iz *Gamljina, tega pa iz *Gamlja vas k domnevno slov. atn *Gam.

S spletno objavo srednjeveških in novoveških listin iz tolminske cerkvene zgodovine so postali dostopni številni novi podatki o posameznih osebnih imenih na Tolminskem iz tistega časa. V listini iz leta 1447 (Nazzi 2008: 332) sta tako omenjena domačina Themuli et Jebaç de Rutis (*Temel in *Jebač iz Ruta). Themulus je polatinjeni zapis nem. imena Thömel, kar je nem. hpk od imena Thomas (Bahlow 1972: 88). Prim. še zapisa Themle schneyder za podložnika 1515 v Znojilah (rihtarija Rut) in Peter Themel za isto osebo 1523 (Torkar 2003: 106), priimek Temlin in že izumrle priimke Temel, Temelj, Teml, Temle (Bezlaj 1974: 634). Glede na prikazano besedotvorno razčlembo tpn Temljine in glede na stan. i. Temljani je povsem dopustno rekonstruirati to ime kot *Temljina, kar je videti poenobesedeno iz *Temlja vas, to pa izpeljano iz hpk *Temel. Tpn Temljine in s tem verjetno tudi naselje samo sta najverjetneje nastala šele v drugi polovici 13. stol., ko se je v Baški dolini z doselitvijo Tirolcev (malo pred 1. 1250) opazno povečal nemški jezikovni vpliv (Torkar 2006: 96). To je bil tudi sicer na Slovenskem čas, ko so nastajala hibridna krajevna imena, v katerih je podstava nem. antroponim, izpeljava pa slovenska, npr. Gameljne, Pirniče, Vikrče, Pokrče, Žoprače, Ruperče. Zapisi Telmine poleg Temline in tudi narečna raba izkazujejo nihanje med predpostavljeno prvotno obliko *Temljina in metatezirano množinsko narečno obliko Teljmine.

\section{Kallenberg, nem. ime za Šmarno goro}

Šmarna gora, hrib v bližini Ljubljane, je v virih prvič izpričana leta 1296 kot Sanctus Martinus sub Monte Sancte Marie, ${ }^{3}$ medtem ko poznejši zapisi, začenši z letom 1314, hrib navajajo s starim slovenskim imenom *Holm: capellae beatae Mariae Virginis in monte qui dicitur Cholemperh, 1341 in monte Colemperch, 1372 vnder dem Chollenperg,

3 Celotno ime označuje Šmartno pod Šmarno goro. V starejši literaturi se je kot prva omemba Šmarne gore zmotno navajal Marienberch v listini iz 1. 1216, za katerega se je izkazalo, da se nanaša na Marenberch, danes Radlje ob Dravi, gl. Šilc 2015: 179. 
1393 auf dem Cholmperg, 1403 in Kallemberg, 1411 in monte Kollenperg, 1419 am Kollenpergk, 1436 vnder dem Kholnperg, 1450 an dem grossen Kollenperg, 1453 aufdem Kallenperg, 1456 Cholmperg, 1475 in monte Colemberg, 1499 in monte vulgariter nuncupato Collenpergk, 1689 auf dem Kohlenberge (na Jhemarne gore), 1744 Kallenberg, 1780 Smarten Gora oder Gros Gallenberg, 1826 Grofs Gallenberg. Tudi kraj Homec južno od Kamnika ima zapise 1238 Chvlniz, 1252 Chvlm, 1256 Kulmetz, 1258 Chumtz, 1287 Choumcz, 1390 vnder dem chlainen Chollenperg, 1428 Kollenberg, 1490 Klaine Comecz, 1744 Klein Kalenberg in Humez, 1780 Kl. Kalenberg. Nemški pisarji so slovenskemu gorskemu imenu *Holm dodali še nemško oznako Berg, zato je nastala oblika Cholemperg, kasneje z disimilacijo Kollenberg in slednjič Kallenberg, s preosmišljenjem oz. naslonitvijo na prid. kahl 'gol'. Vsaj že geograf in zgodovinar Orožen (1901: 60) je, sklicujoč se na najstarejše zapise Šmarne gore, ugotavljal, da je njeno prvotno ime Holm, enako pa pozneje tudi avtorji KLDB (1937: 358) in Badjura (1953: 114), ${ }^{4}$ medtem ko Ramovš, Bezlaj in Snoj tem preosmišljanjem niso namenili pozornosti.

\section{Seznam krajšav}

$\begin{array}{ll}\text { atn } & \text { - antroponim, antroponimski } \\ \text { hpk } & \text { - hipokoristik, hipokoristični } \\ \text { tpn } & \text { - toponim } \\ \text { k.o. } & \text { - katastrska občina } \\ \text { o. } & \text { - občina } \\ \text { nem. } & \text { - nemški (-o) } \\ \text { os. i. } & \text { - osebno ime } \\ \text { psl. } & \text { - praslovanski (-o) } \\ \text { slov. } & \text { - slovenski (-o) } \\ \text { stvn. } & \text { - starovisokonemški } \\ \text { apel. } & \text { - apelativ } \\ \text { prid. } & \text { - pridevnik }\end{array}$

\section{Viri}

BEZLAJ, France (red.) (1974) Začasni slovar slovenskih priimkov. Ljubljana: Inštitut za slovenski jezik.

JAKOPIN, Franc idr. (1985) Slovenska krajevna imena. Ljubljana: Cankarjeva založba. KOS, Milko (1948) Srednjeveški urbarji za Slovenijo. Zvezek drugi. Urbarji Slovenskega Primorja. 1. del. Ljubljana: Akademija znanosti in umetnosti.

KLDB (1937) Krajevni leksikon dravske banovine. Ljubljana: Uprava Krajevnega leksikona dravske banovine.

4 Badjura k temu dodaja: Prav bi bilo, da ji njeno častitljivo staro ime vrnemo, saj je prav izrazit, šolski primer holma! 
METELKOVO GRADIVO (1823) Seznami krajevnih imen na Gorenjskem, Dolenjskem in v Beljaškem okrožju v nemščini in slovenščini, pripravljeni za Metelka leta 1823, rokopisna zbirka NUK, MS 416.

NAZZI, Faustino (2009) Storia religiosa della Slavia Friulana dalle origini al 1920, spletni vir: http://fauna31.wordpress.com/storia-religiosa-della-slavia-friulana-dalle-origini-al-1920/, razdelek https:/fauna31.files.wordpress.com/2011/02/distrettodi-tolmino-08.pdf.

OROŽEN, Fran (1901) Vojvodina Kranjska. I. Ljubljana: Matica Slovenska.

PKLS (1997) Priročni krajevni leksikon Slovenije. Ur. M. Orožen Adamič, D. Perko, D. Kladnik. Ljubljana: DZS, Založništvo literature.

PLETERŠNIK, Maks (2006) Slovensko-nemški slovar. I-II. Transliterirana izdaja. Ur. M. Furlan. Ljubljana: Založba ZRC.

TTN 5 Temeljni topografski načrt $1: 5.000$ (seznam imen). Geodetska uprava Republike Slovenije.

SCHMUTZ, Carl (1822-1823) Historisch Topographisches Lexikon von Steyermark. I-IV. Gratz: auf Kosten der Verfasser.

Spletni vir 1: http://www.stat.si/KrajevnaImena/

\section{Literatura}

ANB (1989-2004) Altdeutsches Namenbuch. Die Überlieferung der Ortsnamen in Österreich und Südtirol von den Anfängen bis 1200. Wien: Verlag der Österreichischen Akademie der Wissenschaften.

BADJURA, Rudolf (1953) Ljudska geografija. Terensko izrazoslovje. Ljubljana: Državna založba Slovenije.

BAHLOW, Hans (1972) Deutsches Namenlexikon. Frankfurt am Main: Suhrkamp Taschenbuch Verlag.

BEZLAJ, France (1965) »Slovenski imenotvorni proces.« Jezik in slovstvo 10/4-5, 113-118. [Ponatis v: Bezlaj (2003/I), 289-294.]

BEZLAJ, France (1976-2007) Etimološki slovar slovenskega jezika. I-V. Ljubljana: Mladinska knjiga.

BEZLAJ, France (1977)»O imenih Sneberje, Sostro in drugo.« Jezik in slovstvo 22/8, 225-227. [Ponatis v: Bezlaj (2003/I), 572-574.]

BEZLAJ, France (2003) Zbrani jezikoslovni spisi. I-II. Ur. M. Furlan. Ljubljana: Založba ZRC.

ESSJa (1974-2014-) Этимологический словарь славянских языков. Праславянский лексический фонд. 1-39-. Под редакцией академика О. Н. Трубачева (1-32) и д. ф. н. А. Ф. Журавлева (33-39). Москва: Издательство »Наука«.

KELEMINA, Jakob (1944) »Kozarje in Vižmarje.« V: N. Velikonja (ur.), Zbornik zimske pomoči. Ljubljana: Zimska pomoč, 392-393.

KELEMINA, Jakob (1951) »Langobardski spomini pri Slovencih.« Slavistična revija 4/3-4, 177-196. 
KRONSTEINER, Otto (1975) Die alpenslawischen Personennamen. Wien: Österreichische Gesellschaft für Namenforschung.

LOCHNER V. HÜTTENBACH, Fritz (2008) Ortsnamen in der Steiermark. Zur Herkunft und Deutung von Siedlungs-, Berg-, Gewässer- und Flurbezeichnungen. Graz: Leykam.

MALEC, Maria (1971) Budowa morfologiczna staropolskich złożonych imion osobowych. Wrocław/Warszawa/Kraków/Gdańsk: Zakład Narodowy imienia Ossolińskich/Wydawnictwo Polskiej Akademii Nauk.

MALEC, Maria (2003) Slownik etymologiczny nazw geograficznych Polski. Warszawa: Wydawnictwo Naukowe PWN.

MIKLOŠIČ, Fran (1860) »Die Bildung der slavischen Personennamen. «Denkschriften der Kaiserlichen Akademie der Wissenschaften. Philosophisch-historische Classe 10. Wien, 215-330.

PLESKALOVÁ, Jana (1998) Tvořeni nejstaršich českých osobních jmen. Brno: Vydavatelství Masarykovy univerzity.

PROFOUS Antonín (1947-1960) Mistní jména v Čechách, jejich vznik, pưvodní význam a změny. I-V. Praha: Nakladatelství Československé akademie věd.

RAJH, Bernard (2010) Gúčati po antùjoško. Gradivo za narečni slovar severozahodnoprleškega govora. Maribor: Filozofska fakulteta, Mednarodna založba Oddelka za slovanske jezike.

RAMOVŠ, Fran (1924) Historična gramatika slovenskega jezika. II. Konzonantizem. Ljubljana: Učiteljska tiskarna.

ROSPOND, Stanisław (1983) Stowiańskie nazwy miejscowe z sufiksem -jb. Wrocław: Wydawnictwo Uniwersytetu Wrocławskiego.

SCHWARZ, Ernst (1960) Sprache und Siedlung in Nordostbayern. Nürnberg: Verlag Hans Carl.

SKOK, Petar (1924) »Tri etimologije.« Časopis za slovenski jezik, književnost in zgodovino $4,38-46$.

SNOJ, Marko (2009) Etimološki slovar slovenskih zemljepisnih imen. Ljubljana: Modrijan/Založba ZRC.

ŠILC, Jurij (2015) »Gradiščan na Šmarni gori, ki to ni bil. Listina s prvo omembo Zbilj iz leta 1216.« Kronika 63/2, 177-186.

ŠTREKELJ, Karel (1906) »Razlaga nekterih krajevnih imen po slovenskem Štajerju. $1 . «$ Časopis za zgodovino in narodopisje 3, 41-64.

TASZYCKI, Witold (1958) »Najdawniejsze polskie imiona osobowe.« V: isti, Rozprawy $i$ studia polonistyczne. I. Onomastyka. Wrocław/Kraków: Zakład Narodowy imienia Ossolińskich/Wydawnictwo Polskiej Akademii Nauk, 32-148.

TOPOROV, Vladimir (1993) Топоров, Владимир Николаевич, »Праславянская культура в зеркале собственных имен (элемент *mir-).« V: Г. Г. Литаврин (odg. ur.), История, культура, этнография и фольклор славянских народов. XI Международный съезд славистов. Москва: Наука, 3-118.

TORKAR, Silvo (2003) Zgodovinska antroponimija vzhodne Tolminske. Magistrsko delo. Ljubljana. 
TORKAR, Silvo (2006) »Zemljepisna imena v zgornji Baški dolini.« V: S. Torkar/K. Kofol (ur.), Baški zbornik. Alpski mladinski raziskovalni tabor Podbrdo 1992, 1993 in 1995. Tolmin: Tolminski muzej, 95-106.

TORKAR, Silvo (2011) »Rebusi v slovenski onomastiki.« Slavica Tartuensia IX. Лингвокультурное пространство современной Европы через призму малых и больших языков, 353-362.

TORKAR, Silvo (2012) »Razpoznavanje slovenskih zemljepisnih imen.« Slavistična revija 60/4, 693-707.

TORKAR, Silvo (2015) »Варианты форм с переходом $v>g$ и $b>g$ в словенской топонимии.« V:Е. Л. Березович, Этнолингвистика. Ономастика. Этимология. Екатеринбург: Издательство Уральского университета, 279-282.

TRAUTMANN, Reinhold (1950) Die slavischen Ortsnamen Mecklenburgs und Holsteins. Berlin: Akademie-Verlag.

VALČÁKOVÁ, Pavla (2007) »Имена славянского происхождения в старославянских памятниках.« V: Б. I. Бунчук (znan. ur.), Науковий вісник Чернівецького університету. Випуск 354-355. Словяянська філологія. Збірник наукових праць. Чернівці: "Рута", 23-28.

VASMER, Max (1986-1987) Фасмер, Макс, Этимологический словарь русского языка. Перевод с немецкого и дополнения члена-корреспондента АН СССР О. Н. Трубачева. I-IV. Издание второе, стереотипное. Москва: Прогресс.

ŽUNKOVIČ, Davorin (1927) »Krajevni imeni Stopence in Tezno.« Časopis za zgodovino in narodopisje 22, 75-76.

\section{Povzetek}

\section{NEMŠKO-SLOVENSKI STIKI V SLOVENSKI TOPONIMIJI}

V prispevku se obravnava osem slovenskih zemljepisnih imen, ki so nastala v medjezikovnem stiku, vendar pri treh to velja le za njihove nemške oblike.

Nemci so substituirali ali samo adaptirali slovenska zemljepisna imena, pri čemer so Slovenci v večji ali manjši meri sprejeli nemške oblike svojih imen. Na ta pojav je svoj čas opozoril že Štrekelj, ko je pojasnil krajevno ime Činžat iz slovenskega apel. senožet, mi pa ga ponazarjamo na primerih krajevnih imen Njiverce in Stoperce. Nemci so krajevno ime adaptirali ali prevedli, medtem ko so Slovenci ohranili svojo imensko obliko, ki se je spreminjala v skladu z domačim glasovnim razvojem. Takšen primer predstavljata krajevni imeni Vižmarje in Goriča vas.

Imena s podstavo $\mathrm{v}$ enem jeziku in priponskimi obrazili v drugem so hibridna ali heteromorfna imena. Ta tip imen je na Slovenskem razmeroma pogosten, npr. Ruperče, Pirniče, Gunclje (nemško osebno ime in slovansko obrazilo -jb) ali Prosnid, Jagnjed (slovenska apelativna podstava in starofurlansko obrazilo -ed). V to kategorijo sodijo tudi krajevna imena Vižinga, Ciringa, Temljine in nemška oblika gorskega imena Šmarna gora, ki se glasi Kallenberg.

Ključne besede: nemško-slovenski jezikovni stiki, slovenski toponimi, hibridna imena 


\section{Abstract \\ GERMAN-SLOVENE CONTACT IN SLOVENE TOPONYMY}

The paper analyses eight Slovene toponyms which are the result of a language contact situation - with three of them, however, that only holds for their German counterparts.

Slovene speakers to a lesser or greater extent took over German substitutions and adaptations of Slovene toponyms. This phenomenon has already been noted by Štrekelj in his analysis of the place name Činžat as a derivation from the Slovene appellative senožet. We show this too in the case of the place names Njiverce and Stoperce. It also happened that German speakers adapted or translated a given toponym, while Slovene speakers preserved their own form of the name, which then changed in accordance with Slovene sound change laws. An case in point are the place names Vižmarje and Goriča vas.

Toponyms with a stem from one language and affixes from another are called hybrid or heteromorphic toponyms. The type is relatively common in the Slovene-speaking area, as exemplified by Ruperče, Pirniče, Gunclje (German proper names with the Slavic suffix -jb) or Prosnid, Jagnjed (Slovene appellative stems with the Old Friulian suffix -ed). This category also comprises the place names Vižinga, Ciringa, Temljine and the German counterpart of the Slovene oronym Šmarna gora, i.e. Kallenberg.

Keywords: German-Slovene language contact, Slovene toponyms, hybrid toponyms 